\title{
Photoluminescence, Photoabsorption and Photoemission Studies of Hydrazone Thin Film used as Hole Transporting Material in OLEDs
}

\author{
W. G. Quirino, ${ }^{a}$ C. Legnani, ${ }^{a}$ M. Cremona, ${ }^{a}$ R. Reyes,,${ }^{a, c}$ G. V. Mota, ${ }^{b, d}$ D. E. Weibel ${ }^{b, e}$ and M. L. M. Rocco ${ }^{*, b}$ \\ ${ }^{a}$ Departamento de Física, Pontifícia Universidade Católica do Rio de Janeiro, \\ 22453-970 Rio de Janeiro-RJ, Brazil
}

${ }^{b}$ Instituto de Química, Universidade Federal do Rio de Janeiro, 21949-900 Rio de Janeiro-RJ, Brazil

${ }^{c}$ Facultad de Ingeniería Química y Manufacturera, Universidad Nacional de Ingeniería, Av. Tupac Amaru SN, Lima, Perú

${ }^{d}$ Instituto de Física, Universidade Federal de Sergipe, 49100-000 São Cristóvão-SE, Brazil

${ }^{e}$ Instituto de Química, Universidade Federal do Rio Grande do Sul, 91501-970 Porto Alegre-RS, Brazil

\begin{abstract}
A fotoluminescência de filmes finos de 1-(3-metilfenil)-1,2,3,4-tetrahidroquinolina-6carboxialdeído-1,1'-difenilhidrazona foi monitorada em função da irradiação com luz UV. A intensidade da emissão decresce exponencialmente com o tempo de exposição, sugerindo degradação das amostras. Com o objetivo de investigar os mecanismos de degradação e determinar a estrutura eletrônica desse material orgânico usado com sucesso como camada transportadora de buracos na fabricação de diodos orgânicos emissores de luz (OLEDs), foram empregadas as técnicas de fotoabsorção e de fotoemissão nas bordas 1s do carbono e do nitrogênio bem como na banda de valência. A influência da luz solar foi simulada usando radiação síncrotron não-monocromática. Após exposição, todos os espectros apresentam um decréscimo nos sinais de fotoabsorção e de fotoemissão, que é menos acentuado na borda do carbono, apresentando, entretanto, um decréscimo drástico na borda do nitrogênio e na região de valência. O estudo sugere que a perda de nitrogênio é a principal causa para a quebra do sistema $\pi$, levando, dessa forma, à falha do dispositivo fabricado com esse composto.
\end{abstract}

Photoluminescence (PL) emission of 1-(3-methylphenyl)-1,2,3,4-tetrahydroquinoline-6carboxyaldehyde-1,1'-diphenylhydrazone (MTCD) thin films was monitored as a function of UV irradiation, and it was found to decrease exponentially with the exposure time. In order to gain insight into the degradation mechanisms and evaluate the electronic structure of this organic material used with good results as hole transporting layer (HTL) in the fabrication of organic light emitting diodes (OLEDs), synchrotron radiation-based photoabsorption and photoemission techniques at the carbon and nitrogen 1 s edges as well as at the valence band were employed. The influence of sunlight was simulated using non-monochromatized synchrotron radiation. After exposure all the spectra show a decrease of the photoabsorption and photoemission signals, however, while it is less accentuated at the carbon edge, at the nitrogen edge and at the valence region it decreases drastically. The loss of nitrogen is suggested to be the main step in the disruption of the $\pi$ system, leading to the failure of the devices fabricated with this compound as hole transporting layer.

Keywords: photoluminescence, photoabsorption, photoemission, MTCD, OLED degradation

\section{Introduction}

In the last decades a growing research activity has been dedicated to the development of solid state miniaturized light sources and to the fabrication of compacts optoelectronic and photonic devices. Together

\footnotetext{
*e-mail: luiza@iq.ufrj.br
}

with an extensive investigation in inorganic semiconductors, there has been a huge development in the last years of the research activities to obtain integrated light sources based on organic materials. Due to their applications in many different areas and manufacturing simplicity, organic light emitting diodes (OLEDs) represent a promising research line in the development of new optoelectronic devices. ${ }^{1}$ However, the degradation of the organic materials which 
are commonly used in the OLED fabrication is still the principal weakness of these devices. Many efforts have been made in order to understand the factors that influenced the different degradation mechanisms of the OLEDs and their organic materials, principally for TPD [ $N, N^{\prime}$-diphenyl$N, N^{\prime}$-bis(3-methylphenyl)-1,1'-biphenyl-4,4'-diamine] and $\mathrm{Alq}_{3}$ [tris-(8-hydroxyquinoline) aluminum]..$^{2-6}$

Another important aspect of the OLED operational stability, especially for the implementation in portable devices, is their stability against radiation originated from the environment, such as intense sunlight. In order to better understand the degradation processes which occur when these organic materials are submitted to intense radiation a series of investigations using spectroscopic techniques were carried out.

In the present work photoluminescence (PL) emission, X-ray photoabsorption (NEXAFS - Near-edge X-ray absorption fine structure) and valence band and corelevel photoemission (XPS - X-ray photoelectron spectroscopy) results were obtained for 1-(3-methylphenyl)1,2,3,4-tetrahydroquinoline-6-carboxyaldehyde-1,1'diphenylhydrazone (MTCD) in form of thin films. This kind of organic material has been used with good results as hole transporting layer in the fabrication of OLEDs. The influence of sunlight was simulated using broadband synchrotron radiation.

\section{Experimental}

Photoluminescence (PL) emission of 1-(3-methylphenyl)1,2,3,4-tetrahydroquinoline-6-carboxyaldehyde-1,1'diphenylhydrazone (MTCD) thin films was obtained using a spectrofluorimeter (Photon Technology International, model 1469) with an incident intensity of $1 \mathrm{~mW} \mathrm{~cm}^{-2}$, also used to monitor simultaneously PL emission as a function of UV excitation/exposure time.

Photoabsorption and photoemission experiments were performed at the Brazilian Synchrotron Light Source (LNLS), located in Campinas, São Paulo. The SGM beamline, mounted with a spherical grating monochromator for VUV and Soft X-ray Spectroscopy (250-1000 eV), gives an energy resolution $(\mathrm{E} / \Delta \mathrm{E})$ better than 2000 . The spot size on the sample was about $0.5 \times 0.5 \mathrm{~mm}^{2}$. The experimental set-up includes a sample manipulator and a concentric hemispherical electron energy analyzer housed in an UHV chamber with a base pressure of $10^{-9}$ mbar. The organic materials in form of thin films were attached directly to the sample holder using a conducting double side tape. In addition, silver glue was used in the corners of the samples to assure for a good electrical contact. No sample charging was observed throughout the experiments.
The energy calibration was performed by taking the well known values for the $4 \mathrm{f}_{7 / 2}$ and $4 \mathrm{f}_{5 / 2}$ transitions at 83.9 and $87.9 \mathrm{eV}$, respectively, of a clean gold foil in electrical contact with the sample holder. ${ }^{7}$ The photoemission spectra were obtained with an energy step of $0.5 \mathrm{eV} / \mathrm{channel}$, while the photoabsorption spectra were measured with $0.2 \mathrm{eV} / \mathrm{channel}$ and $1 \mathrm{~s}$ per point.

The organic films, with $50 \mathrm{~nm}$ thickness, were deposited by thermal evaporation onto indium tin oxide (ITO) covered glass substrates, at room temperature. The substrates were supplied by Asahi Glassa Co., with a sheet resistance of $8.1 \Omega / \square$. They were initially cleaned by ultrasonification using a detergent solution, followed by toluene degreasing and finally cleaned again by ultrasonification with pure isopropyl alcohol. The base pressure was $9 \times 10^{-6}$ mbar during evaporation and the rate of deposition was in the range of 0.1 to $0.3 \mathrm{~nm} \mathrm{~s}^{-1}$. MTCD was used as obtained from Prof. Sung Hoon Kim of the Department of Dyeing and Finishing, Kyngpook National University, Taegu, Korea. Figure 1 shows the molecular structure of MTCD.

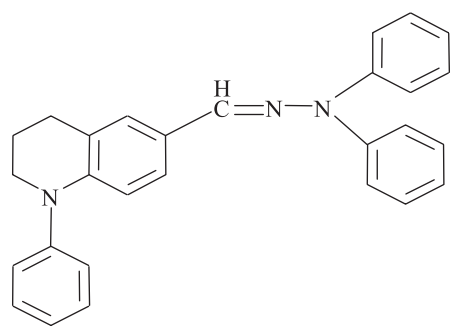

Figure 1. Molecular structure of 1-(3-methylphenyl)-1,2,3,4tetrahydroquinoline-6-carboxyaldehyde-1,1'-diphenylhydrazone, MTCD.

\section{Results and Discussion}

Figure 2a shows PL emission spectra of MTCD obtained upon UV irradiation using the spectrofluorimeter lamp, peaked at $379 \mathrm{~nm}$. As can be observed, the emission spectra present a broad band centered at about $460 \mathrm{~nm}$, whose intensity decreases continuously as a function of the UV exposition time. This behavior could be described by an exponential attenuation with a constant time of $\tau=45.8 \mathrm{~min}$ (Figure 2d). This result may indicate that MTCD is less damaged by UV irradiation compared with other organic electroluminescent materials, like $\mathrm{Alq}_{3}$ and the europium complex, tris(thenoyltrifluoroacetonate) bis(triphenylphosphine oxide) europium, $\left[\mathrm{Eu}(\mathrm{TTA})_{3}(\mathrm{TPPO})_{2}\right],{ }^{8-11}$ of which degradation spectra are shown in Figure $2 b$ and Figure $2 \mathrm{c}$, respectively. Figure $2 \mathrm{~d}$ summarizes the degradation behavior of the three compounds. 

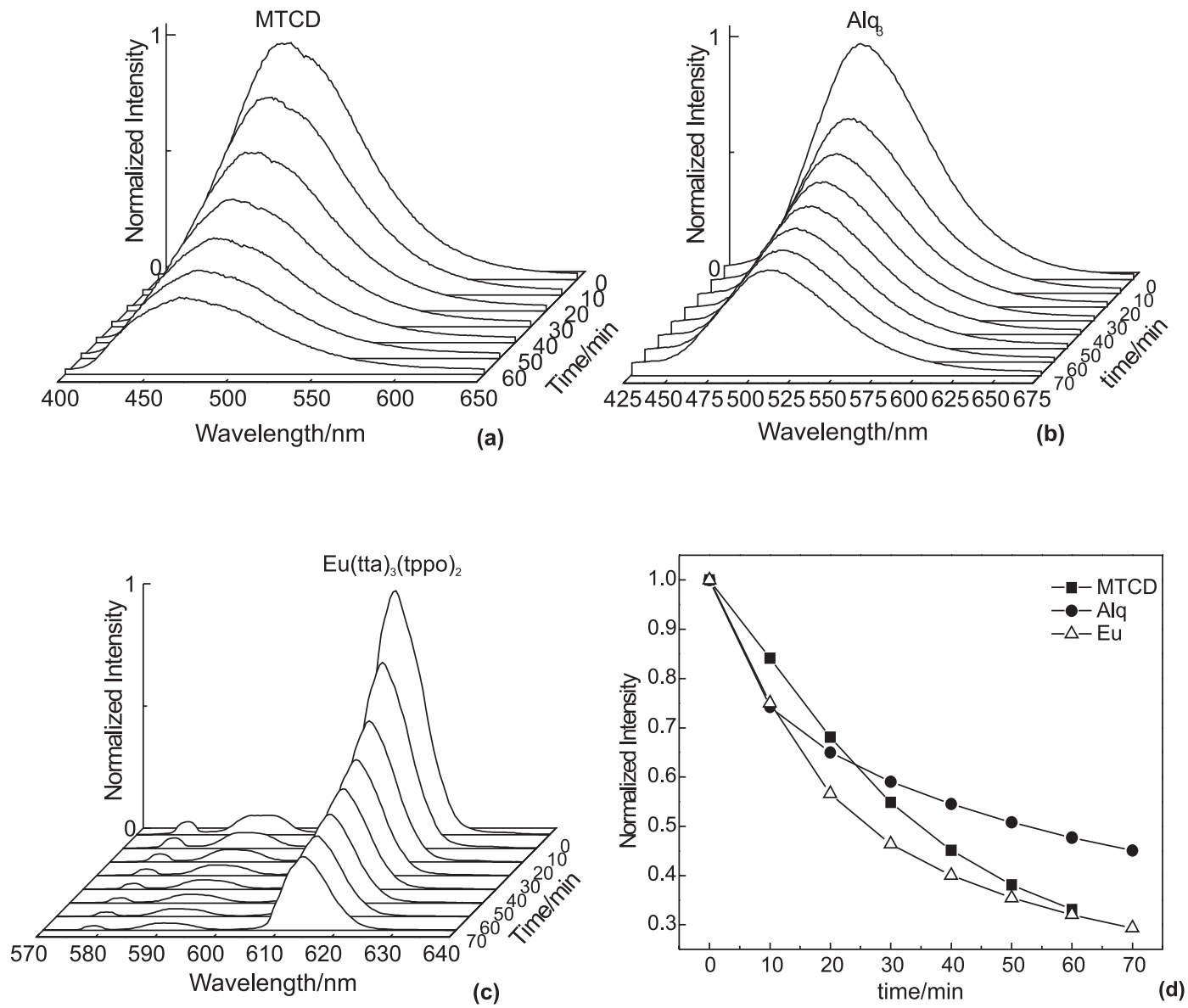

Figure 2. A 3D view emission intensity as a function of UV irradiation of (a) MTCD, (b) $\mathrm{Alq}_{3}$ and (c) Eu(tta) $)_{3}(\mathrm{tppo})_{2}$. A comparison of the decrease of the intensities is shown in (d).

In order to gain insight into the causes of the PL decrease observed in the spectra of Figure 2a when MTCD is submitted to UV irradiation during a long period of time, spanning from 0 to $60 \mathrm{~min}$, we performed photoabsorption and photoemission studies. To simulate the damage produced in the molecular film during long term irradiation, we have carried out photodegradation experiments, exposing the MTCD film to broadband synchrotron radiation. The intensity of the radiation (including visible, UV and X-rays) was about $10^{10}$ photons s $\mathrm{s}^{-1} \mathrm{~cm}^{-2}$ and the film was irradiated for $20 \mathrm{~min}$. Photoabsorption and photoemission spectra were measured before and after exposure.

Near-edge X-ray Absorption Fine Structure (NEXAFS) spectra of MTCD were obtained following the nitrogen $K$-edge (Figure 3), covering from 390 to $440 \mathrm{eV}$ photon energy. They were obtained before (solid line) and after (close circles line) 20 min of photon irradiation. Before irradiation the spectrum shows five features, which corresponds to electronic transitions from the $\mathrm{N} 1 \mathrm{~s}$ electron to unoccupied molecular orbitals. In the absence of theoretical calculations, we suggest that the sharp peak at
$397.8 \mathrm{eV}$ is associated to a transition from the $\mathrm{N} 1 \mathrm{~s}$ electron to a $\pi^{*}$ orbital. The other features may be associated to higher energy excitations, probably containing Rydberg character, and to $\sigma^{*}$ shape resonances.

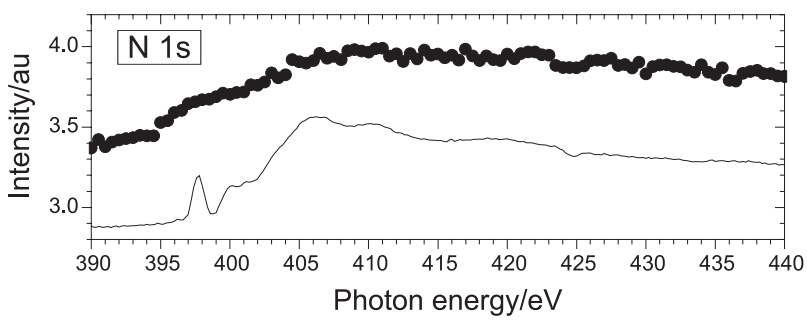

Figure 3. Photoabsorption spectra of MTCD at nitrogen $K$-edge, before (solid line) and after (close circles line) irradiation with broadband synchrotron radiation.

As can be seen from Figure 3 the intensity and shape of the peaks change drastically upon irradiation, showing evidence of strong degradation associated with the loss of the nitrogen atoms due to the incident radiation. This result is corroborated by XPS spectra obtained for nitrogen 1s level, which are displayed in Figure 4 before (solid line) and 
after (close circles line) non-monochromatized synchrotron irradiation. The XPS results show that the nitrogen signal decreased to zero after irradiation. The carbon 1s XPS spectra were also measured and they are plotted in Figure 5 before (solid line) and after (close circles line) irradiation. Basically they show a decrease in intensity together with a shift of the photoelectric peak to lower binding energy after irradiation with intense synchrotron radiation. This behavior can be explained by the formation of new carbon containing species, as observed for $\mathrm{Alq}_{3}{ }^{4}$ Although MTCD has unequivalent nitrogen and carbon atoms it was not possible to distinguish them due to the low resolution at the present experimental conditions. The damage produced by the irradiation affects directly the valence band (see Figure 6), where there is a dramatic change in the occupied electronic structure leading to the disappearance of almost all original transitions. These effects can be ascribed to the fact that valence orbitals are very much sensitive to changes in the bonding environment. Comparing these results we have that the $\mathrm{N}$ 1s photoemission signal was reduced $100 \%$ of the original intensity, carbon only about $30 \%$ and the valence orbitals presented $50 \%$ of degradation.

As discussed before MTCD showed a complete decrease in the nitrogen photoabsorption and photoemission signals after exposure to broadband radiation. The loss of $\mathrm{N}$ suggests that MTCD mainly decompose by ejection of nitrogen out of the molecule, i.e., by decomposing at the nitrogen containing bonds. The loss of nitrogen disrupts the conjugated $\pi$ system and therefore the charge conduction through the molecule is interrupted, causing damage to the performance of the device. Similar results were found for the $\mathrm{Alq}_{3}$ and TPD molecules. ${ }^{4}$

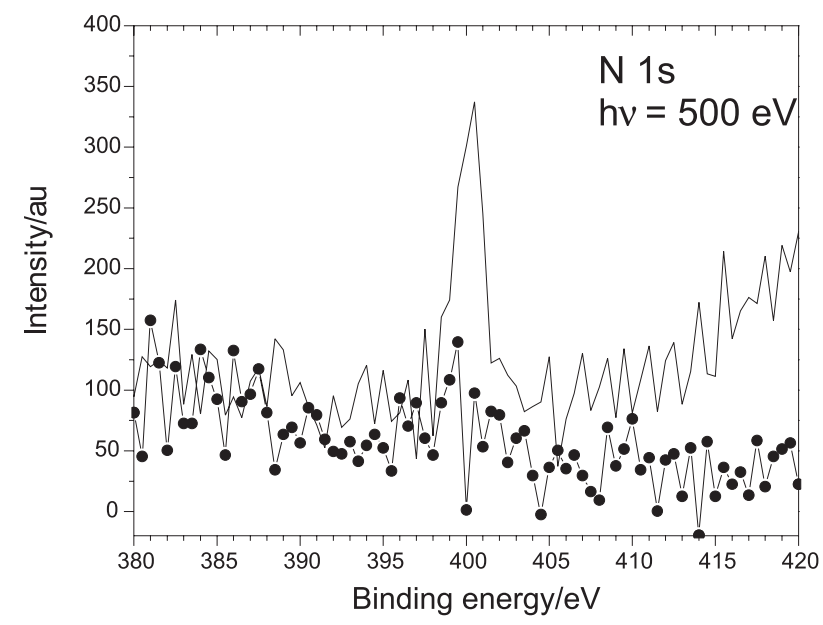

Figure 4. N 1s photoemission spectra of MTCD (hv $=500 \mathrm{eV})$, before (solid line) and after (close circles line) irradiation with broadband synchrotron radiation.

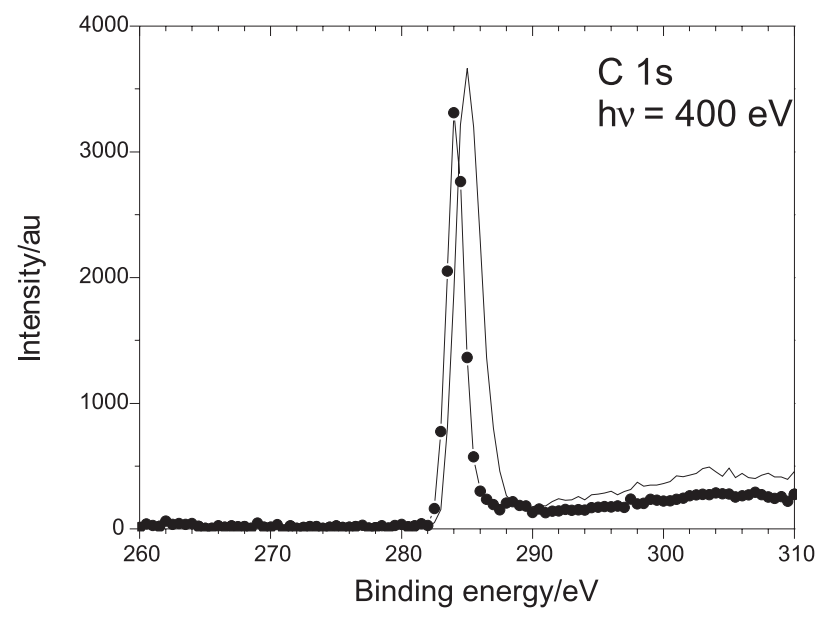

Figure 5. C $1 \mathrm{~s}$ photoemission spectra of MTCD $(\mathrm{h} v=400 \mathrm{eV})$, before (solid line) and after (close circles line) irradiation with broadband synchrotron radiation.

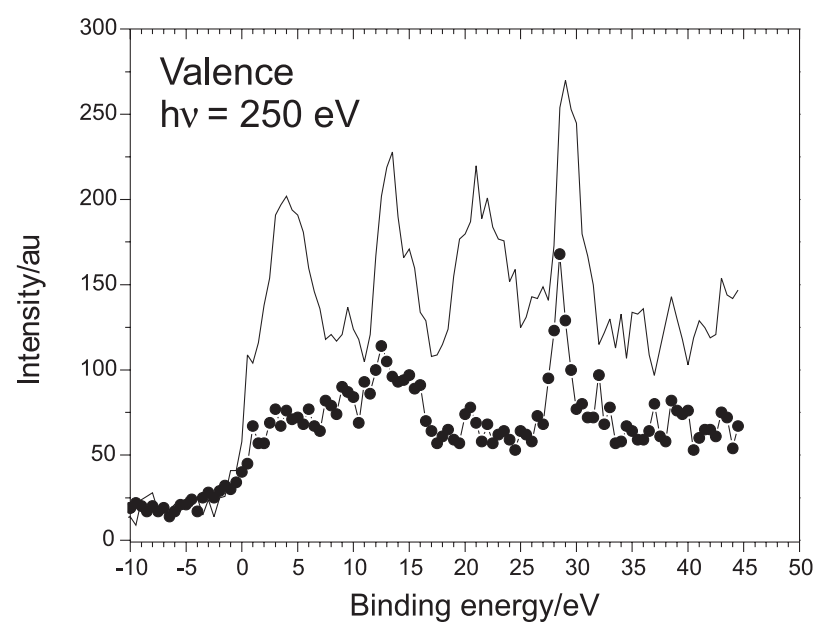

Figure 6. Valence band photoemission spectra of MTCD $(\mathrm{hv}=250 \mathrm{eV})$. The solid line curves were obtained before irradiation with broadband synchrotron radiation, while the close circles line was recorded after 20 minutes irradiation.

\section{Conclusions}

We have monitored the photoluminescence signal of MTCD as a function of UV exposure. The observed effect is an exponential decreasing of the PL emission, with a constant time of $45.8 \mathrm{~min}$. In order to investigate the cause of this effect, MTCD films were exposed to intense synchrotron radiation and studied through spectroscopic techniques. The results showed a complete decrease of the nitrogen 1s photoabsorption and photoemission signals after broadband synchrotron irradiation. The loss of $\mathrm{N}$ suggests that it decomposes mainly by ejecting nitrogen out of the molecule, leading to a breakdown of charge conductivity. It was also shown that the valence band structure changes 
dramatically upon irradiation, reflecting its sensitivity to changes in the bonding environment. We hope that theses studies contribute to the understanding of the irradiation damage mechanisms in MTCD, an organic material used in OLEDs as hole transport layer and might help in the manufacturing of new molecules with applications in OLEDs.

\section{Acknowledgments}

Research partially supported by LNLS - National Synchrotron Light Laboratory, Brazil. The authors would like to acknowledge RENAMI, CNPq, CAPES, FAPERJ, and FAPESP for financial support, Prof. Sonia R. W. Louro (PUC-Rio) for the use of the spectrofluorimeter, and Prof. Sung-Hoon Kim of the Kyungpook National University (Korea) for providing the MTCD.

\section{References}

1. Sheats, J. R.; Antoniadis, H.; Hueschen, M.; Leonard, W.; Miller, J.; Moon, R.; Roitman, D.; Stocking, A.; Science 1996, 273, 884.

2. Burrows, P. E.; Bulovic, V.; Forrest, S. R.; Sapochak, L. S.; McCarty, D. M.; Thomson, M. E.; Appl. Phys. Lett. 1994, 65, 2922.
3. Popovic, Z. D.; Aziz, H.; Hu, N.; Hor, A.; Xu, G.; Synth. Metals 2000, 111-112, 229.

4. Treusch, R.; Himpsel, F. J.; Kakar, S.; Terminello, L. J.; Heske, C.; Buuren, T.; Dinh, V. V.; Lee, H. W.; Pakbaz, K.; Fox, G.; Jiménez, I.; J. Appl. Phys. 1999, 86, 88.

5. Curiori, A.; Andreoni, W.; Treusch, R.; Himpsel, F. J.; Haskal, E.; Seidler, P.; Heske, C.; Kakar, S.; van Buuren, T.; Terminello, L. J.; Appl. Phys. Lett. 1998, 72, 1575.

6. Liao, L. S.; Hung, L. S.; Chan, W. C.; Ding, X. M.; Sham, T. K.; Bello, I.; Lee, C. S.; Appl. Phys. Lett. 1999, 75, 1619.

7. Wagner, C. D.; Riggs, W. M.; Davis, L. E.; Moulder, J. F.; Muilenber, G. E.; Handbook of X-ray Photoelectron Spectroscopy, Perkin-Elmer Corporation: USA, 1979.

8. Reyes, R.; da Silva, C. F. B.; de Brito, H. F.; Cremona, M.; Braz. J. Phys. 2002, 32, 535.

9. Reyes, R.; Cremona, M.; Teotônio, E. E. S.; Brito, H. F.; Malta, O. L.; Thin Solid Films 2004, 469-470, 59.

10. Reyes, R.; Hering, E. N.; Cremona, M.; da Silva, C. F. B.; Brito, H. F.; Achete, C. A.; Thin Solid Films 2002, 420-421, 23.

11. Reyes, R.; Hering, E. N.; Cremona, M.; Brito, C. F.; Brito, R. T.; Achete, C. A.; Phys. Stat. Sol. (C) 2004, 1-S2, S229.

Received: September 19, 2007

Web Release Date: April 18, 2008 